\title{
Long-term maintenance therapy with Cyclosporine $A$ in adults with generalized pustular psoriasis
}

\author{
Kamel El-Reshaid *, Shaima Al-Bader ** \\ *Department of Medicine, Faculty of Medicine, Kuwait University, P O Box 24923, 13110 Safat, Kuwait \\ **Asad Al-Hamad dermatology center, Ministry of health, Kuwait
}

\begin{abstract}
Generalized pustular psoriasis (GPP) is a rare and serious immune-mediated skin disorder that is characterized by a widespread eruption of sterile and subcorneal pustules. In the present study we investigated the efficacy of Cyclosporine A (Cy A) in treatment of 9 adults with drugrefractory GPP viz. topical Corticosteroids, retinoids, methotrexate and narrow-band ultraviolet light exposure (UVB). Initially; they were resuscitated as burn patients. Cy A was administered on day 1 at a dose of $100 \mathrm{mg}$ twice daily either in the form of syrup or Neoral capsules. In most patients, skin lesions had healed by 6 weeks and the dose of Cy A was reduced to minimum to prevent further recurrence. Seven patients had required $50 \mathrm{mg}$ twice daily and 2 were controlled with $50 \mathrm{mg}$ am and $25 \mathrm{mg} \mathrm{pm}$. On follow up, there was no serious relapse, liver and kidney disease. Minor complications included; hirsutism and dark skin (n: 5) and gingival hyperplasia (n: 2). Trial to replace Cy A with Tacrolimus (Prograf) failed to maintain remission. In conclusion; Cy A is a safe and effective treatment for GPP.
\end{abstract}

Keywords: Cyclosporin A, treatment, psoriasis, pustular.

Article Info: Received 07 July 2019; Review Completed 16 August 2019; Accepted 29 August 2019; Available online 15 Sep 2019

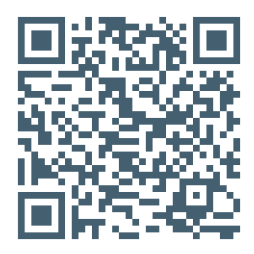

Cite this article as:

El-Reshaid K, Al-Bader S, Long-term maintenance therapy with Cyclosporine A in adults with generalized pustular psoriasis, Journal of Drug Delivery and Therapeutics. 2019; 9(5):19-21 http://dx.doi.org/10.22270/jddt.v9i5.3535

*Address for Correspondence:

Dr. Kamel El-Reshaid, Professor, Dept. of Medicine, Faculty of Medicine, Kuwait University, P O Box 24923, 13110 Safat, Kuwait

\section{INTRODUCTION}

Psoriasis (P) is a common skin disease affecting $2 \%$ of people living in the United States. It is an autoimmune disease with genetic predisposition associated with multiple triggering environmental factors [1]. Plaque and guttate types are the most common presentations of $\mathrm{P}$ and both account for over $90 \%$ of cases. On the other hands, Pustular type is a rare and serious form of P. It is characterized by a widespread eruption of sterile, subcorneal pustules. It has a reported annual incidence rate of less than 1 per $1,000,000$ inhabitants and prevalence less than 2 per 1,000,000 populations. It affects all races with an equal sex predisposition and the average age of patients is 50 years [2]. It may rarely affect children between 2-10 years yet contrary to adults it may remit with time [3]. It can present with limited and chronic lesions viz. ring-shaped (annular, or circinate), palms and soles (palmoplanter pustulations), fingertips and nails (acrodermatitis continua of Hallopeau) and very rarely in infants. Two serious presentations of pustular $\mathrm{P}$ were reported viz. during pregnancy (impetigo herpetiformis) and generalized pustular P (GPP). The latter may present suddenly, and without history of $P$, with wide spread lesions associated with systemic febrile illness (von Zumbusch type) [4]. The chronic forms of $\mathrm{P}$ are associated with social maladjustment and psychological disorders while the serious ones are associated with high morbidity and ISSN: 2250-1177 mortality due to the inhererent side-effects of immunosuppressive therapy, malnutrition and infections [2]. In our prospective study, we aimed at providing a safe modality for management of the most serious one viz. GPP by using maintenance Cyclosporine A (Cy A).

\section{PATIENTS AND METHODS}

During the period January 2014 to December 2019, 9 adult patients with refractory GPP were selected for treatment with CyA. Patients were included if they had: (a) age $>14$ years; (b) GPP diagnosed clinically and confirmed by histopathological examination; (c) severe and extensive disease with psoriasis area and severity index (PASI) $>70$ [5]; (d) persistent or relapsing disease despite treatment with topical Corticosteroids, retinoids, methotrexate and narrow-band ultraviolet light exposure (UVB); (e) no evidence of recent or recurrent exposure to solar or traumatic injuries, primary skin infections, HIV, drugs viz. lithium, beta blockers, antimalarial, antibiotics (penicillin and sulphonamides), psychotropic agenys (nitrazepam and trazodone), amiodrone, Mestranol, Morphine, NSAIDS and sudden withdrawal of corticosteroids. Initially, all patients were treated, as burn cases, with intravenous fluids with/without human albumin to control shock-state and replace the deficient electrolytes. They also had received broad-spectrum antibiotics to protect against skin and chest 
infections as well as topical treatments. Cy A was given, on day 1 , orally, as syrup or neural capsules, in an initial dose of $3 \mathrm{mg} / \mathrm{kg} /$ day in 2 divided doses. Subsequently, the dose was further adjusted every 2 weeks to achieve a trough level within therapeutic range (100-400 ug/L; Abbott Architect Chemiluminescent Microparticle immunoassay). After their initial in-hospital stabilization, patients were assessed every 2 weeks as outpatients for 6 weeks. They were assessed clinically using PASI scores and with laboratory tests that included complete blood count as well as renal and liver function tests. After 6 weeks of stabilization; patients were seen on monthly basis and the dose of Cy A was reduced gradually, by $25 \mathrm{mg} /$ day every month, till reaching the minimal maintenance dose.

\section{RESULTS}

The demographical data on the patients studied and their response to Cy A after 6 weeks and by the end of the study is summarized in Table 1 . All patients were white adults and with equal sex distribution. They had severe psoriasis for a median of 5 months yet it was refractory to the abovementioned conventional treatments. In most patients, skin lesions had healed rapidly within 6 weeks and PASI scores had dropped from $71.7 \pm 0.5$ to $4.9+1$ by 6 weeks and $3.2 \pm 1$ after $43.4 \pm 9$ months of follow up. Subsequently, the dose of Cy A was reduced gradually to minimum to prevent further recurrence. Seven patients had required $50 \mathrm{mg}$ twice daily and 2 were controlled with $50 \mathrm{mg}$ am and $25 \mathrm{mg}$ pm. On follow up; there was no serious relapse. Their liver and kidney functions were normal. The latter was confirmed by 24 hour urine collections that had shown no significant decrease in creatinine clearance or emergence of significant proteinuria. Minor complications included; hirsutism and dark skin (n: 5) and gingival hyperplasia (n: 2). To avoid such side-effects; Cy A was replaced with Tacrolimus (Prograf). However, Tacrolimus failed to maintain such remissions.

Table. 1 Clinical data on the patients with GPP who had received treatment with Cyclosporine $A$

\begin{tabular}{|c|c|c|c|c|c|c|c|c|c|}
\hline \multirow{2}{*}{$\begin{array}{l}\text { Patient } \\
\text { No. }\end{array}$} & \multirow{2}{*}{$\frac{\text { Age }}{\text { (years) }}$} & \multirow{2}{*}{ Sex } & \multirow{2}{*}{$\frac{\text { Duration of GPP }}{\text { (months) }}$} & \multicolumn{3}{|c|}{ PASI score } & \multirow[t]{2}{*}{ Previous therapy } & \multirow{2}{*}{$\frac{\text { Minimal Cy A dose }}{\text { (mg twice/day) }}$} & \multirow{2}{*}{$\frac{\text { Follow up }}{\text { (months }}$} \\
\hline & & & & Initial & 6 weeks & End & & & \\
\hline 1 & 70 & $\mathrm{M}$ & 12 & 72 & 6 & 3.7 & TS, M, R, UVB & $50+50$ & 60 \\
\hline 2 & 43 & $\mathrm{M}$ & 4 & 70.8 & 4 & 2.1 & $\mathrm{TS}, \mathrm{M}$ & $50+25$ & 52 \\
\hline 3 & 51 & $\mathrm{M}$ & 5 & 72 & 3.9 & 3.3 & TS, M, R, UVB & $50+50$ & 49 \\
\hline 4 & 40 & $\mathrm{~F}$ & 2 & 72 & 3.9 & 2.3 & TS, M & $50+50$ & 48 \\
\hline 5 & 46 & M & 5 & 72 & 6 & 4 & TS, M, R, UVB & $50+50$ & 41 \\
\hline 6 & 35 & $\mathrm{~F}$ & 6 & 72 & 4 & 2 & TS, M, R, UVB & $50+50$ & 38 \\
\hline 7 & 62 & $\mathrm{~F}$ & 4 & 70.8 & 3.9 & 2.3 & TS, M, UVB & $50+50$ & 37 \\
\hline 8 & 56 & $\mathrm{M}$ & 6 & 72 & 6 & 4.4 & TS, M, R, UVB & $50+25$ & 34 \\
\hline 9 & 36 & $\mathrm{~F}$ & 4 & 72 & 6 & 4.6 & TS, M, R, UVB & $50+50$ & 32 \\
\hline
\end{tabular}

Stats* $48.8 \pm 12$

$5(2)$

$71.7 \pm 0.5 \quad 4.9 \pm 1 \quad 3.1 \pm 1$

$43.4+9$

*Age, PASI scores, duration of follow up are expressed in mean+SD while duration of follow up in median (IQ)

Abbreviations: CyA: Cyclosporine A, PASI: Psoriasis Area and Severity Index, IQR: interquartile range, TS: topical steroids, M: Methotrexate, R: Retenoids, UVB: narrow-band ultraviolet light exposure
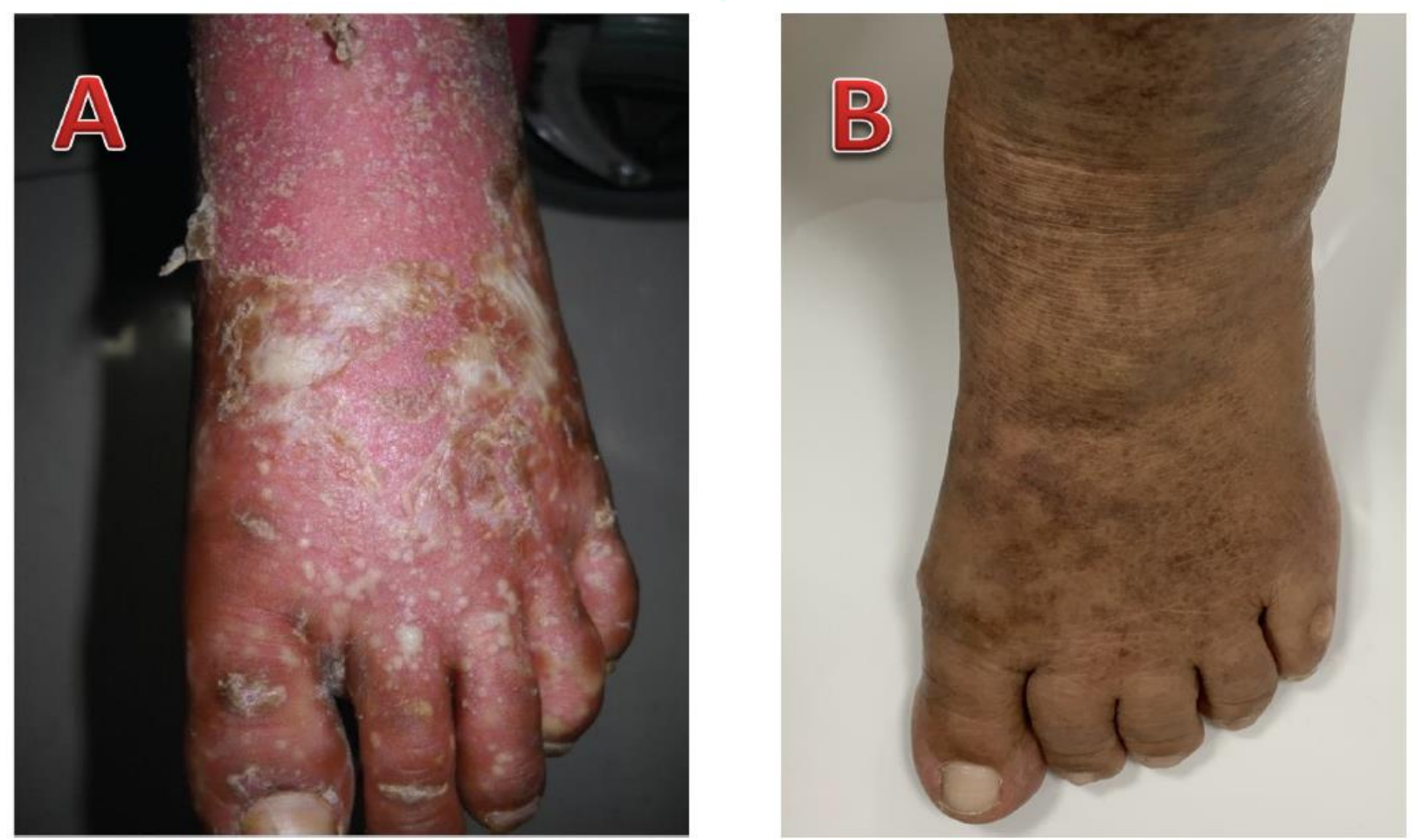

Figure 1 Showing the foot of a patient with generalized pustular psoriasis before (A) and after treatment with Cyclosporine A (B). 


\section{DISCUSSION}

Cy A was first approved to prevent the body from rejecting a transplanted organ. When given to organ-transplant recipients who had psoriasis, patients discovered that the medicine also effectively treated their psoriasis. Since that discovery, the U.S. Food and Drug Administration (FDA) has approved Cy A to treat psoriasis in adults who have extensive or disabling psoriasis [6]. There is now strong circumstantial evidence that psoriatic skin lesions occur when CD4+ $\mathrm{T}$ lymphocytes infiltrate the epidermis of genetically susceptible subjects [7]. The genetic factors predisposing to the psoriatic epidermal response have not been characterized, but are likely to entail abnormal homeostatic control of keratinocyte growth, including hyperproliferative response to products of activated $\mathrm{T}$ lymphocytes [8]. The initiating factor is an injury or microbial infection. The recruited T-lymphocytes infiltrate superficial dermis and produce interleukins and TNF as well as increase production of antigen producing cell (APC). Subsequent cascade of events include; (a) epidermal acanthosis with parakeratosis leading to elongated rete ridges and superficial pinpoint bleeding when the keratin scale peel off easily (b) increase keratin production leading to thick skin and broad scales [9]. In case of pustular P; the neutrophils infiltrate epidermis and collect subcorneal in the acanthotis epidermis leading to sterile pustules. These facts are essential for understanding the role of $\mathrm{Cy} \mathrm{A}$ in treatment of P. The first is its essential role in blocking IL-2 which is essential in the cascade of T-cell recruitment [10]. Hence, it works fast. Moreover, it does not eliminate the disease which is a genetic-predisposition and will be life-long. The latter is essential to avoid recurrence of $\mathrm{P}$ after 120 days following a 4-8 weeks treatment-regimen [11]. As with organ transplant patients; the minimal long-term maintenance dose to avoid relapses is $<3 \mathrm{mg} / \mathrm{kg} /$ day or with a trough levels $<150 \mathrm{ug} / \mathrm{L}$, to minimize risk of interstitial kidney fibrosis [12]. Interestingly, Tacrolimus did not improve GPP as Cy A. Both drugs inhibit the action of the phosphatase calcineurin which regulates the transport of NFAT (nuclear factor of activated T-cells, which is a transcription factor regulating lymphokine gene transcription. However, Cy A and Tacrolimus exert their cellular effects on the action of calcineurin through different cytoplasmatic receptors, as Cy A binds to cyclophilins and Tacrolimus binds to FK-binding proteins [13]. The latter may explain that phenomenon. In conclusion; $\mathrm{Cy} \mathrm{A}$ is an effective and safe maintenance treatment for GPP.

\section{REFERENCES:}

1- Alexis AF, Blackcloud P. Psoriasis in skin of color: epidemiology, genetics, clinical presentation, and treatment nuances. J Clin Aesthet Dermatol. 2014; 7:16-24.

2- Augey F, Renaudier P, Nicolas JF. Generalized pustular psoriasis (Zumbusch): a French epidemiological survey. Eur J Dermatol 2006; 16: 669-673.

3- Popadic S, Nikolic M. Pustular psoriasis in childhood and adolescence: a 20-year single-center experience. Pediatr Dermatol 2014; 31:575-579.

4- Raychaudhuri SK, Maverakis E, Raychaudhuri SP. Diagnosis and classification of psoriasis. Autoimmunity Reviews 2014; 13: 490-495.

5- Schmitt J, Wozel G. The psoriasis area and severity index is the adequate criterion to define severity in chronic plaquetype psoriasis. Dermatology 2005; 210: 194-199.

6- Mueller W, Herrmann B. Cyclosporin A for psoriasis. N England J Med 1979; 301: 555.

7- Sackstein R, Falanga V, Streilein J W, Chin Y H. Lymphocyte adhesion to psoriatic dermal endothelium in is mediated by a tissue-specific receptor/ligand interaction.

J Invest Dermatol 1988; 91: 423-428.

8- Valdimarsson H, Baker B S, Jonsdottir I, Powles A, Fry L. Psoriasis: a disease of abnormal keratinocyte proliferation induced by T lymphocytes. Immunol Today 1986; 7: 256-259.

9- Naik HB, Cowen EW. Autoinflammatory pustular neutrophilic diseases. Dermatol Clin 2013; 31: 405-425.

10- Matsuda S, Koyasu S. Mechanisms of action of cyclosporine. Immunopharmacol 200; 47: 119-125.

11- Okubo Y, Natsume S, Usui K, Amaya M, Tsuboi R. Low-dose, short-term ciclosporine (Neoral) therapy is effective in improving patients' quality of life as assessed by Skindex-16 and GHQ-28 in mild to severe psoriasis patients. J Dermatol 2011; 38:465-472.

12- Slattery C, Campbell E, McMorrow T, Rayan MP. Cyclosporine A-induced renal fibrosis. Am J Pathol 2005; 167: 395-407.

13- Penninga L, Møller CH, Gustafsson F, Steinbrüchel DA, Gluud C. Tacrolimus versus cyclosporine as primary immunosuppression after heart transplantation: systematic review with meta-analyses and trial sequential analyses of randomised trials. Eur J Clin Pharmacol 2010; 66:1177-1187. 